\title{
Coordinated work reveals plant evolution
}

[ST LOUIS] A 'tree of life' giving the most complete picture yet of the evolutionary relationships among all of the Earth's green plants was unveiled last week at the International Botanical Congress in St Louis, Missouri.

The scenario was drawn up by the Green Plant Phylogeny Research Coordination Group, a five-year project involving around 200 scientists from a dozen nations. It is also known as 'Deep Green'.

The team found that plants are divided into four separate kingdoms: green plants the largest group with about 500,000 species, including all land plants and some aquatic plants such as green algae - brown and red seawater plants, and fungi. Interestingly, the fungus kingdom is the closest relative of the animal kingdom, life's fifth kingdom.

Previously, scientists divided life on Earth into animal and plant kingdoms. But the results of the Deep Green project show that, for plants, there are "four lineages of complex, nucleated organisms".

Deep Green researchers also found that all green plants appear to come from a single lineage, not from multiple lineages as previously believed. "This indicates that there's an Eve - a common ancestor - in the primordial soup of green plants," says Brent D. Mishler, a professor of integrative biology at the University of California, Berkeley, and a co-principal investigator of the team.

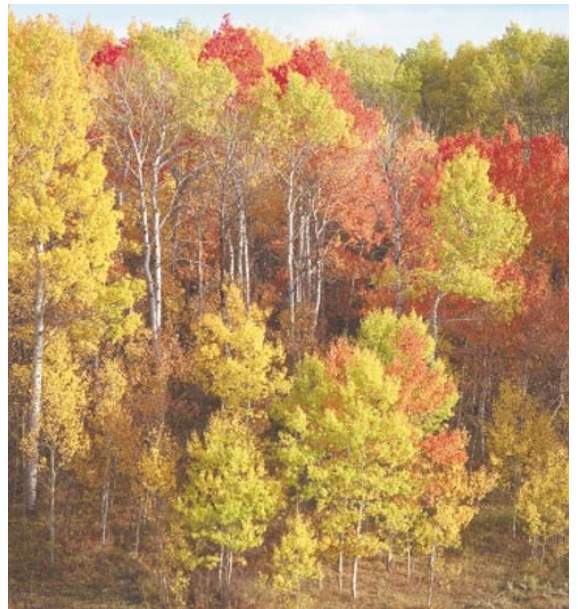

Trees of life: 'plants exist as four kingdoms'.

"A better understanding of this tree of life will allow scientists to better predict the biological properties of plants," says Mishler. "Their economic importance as sources of medicines, structural materials, food and chemicals is immense."

The Deep Green project was described as a classic example of the benefits of interdisciplinary cooperation between scientists, from taxonomists to molecular biologists. "Instead of people jealously guarding their data, they shared data and produced many important discoveries," says Mishler.
Systematists produced data on the evolutionary origin of individual plants, for instance, then molecular biologists refined the species' position on a cladistic tree. This effort "makes a science out of the field of taxonomy", adds Mishler. "Since Darwin, people have been speculating on phylogenetics. This effort gives us methods and explicit data to make comparisons for green plants."

The results of Deep Green's work were presented at eight symposia during the weeklong Botanical Congress, which is held every six years. More than 4,000 scientists attended.

One unexpected discovery was that plant life on land derived from fresh, not salt, water. "This overturns the traditional thinking among scientists and what is taught in every textbook in America," says Mishler.

As universities and schools begin to teach Deep Green scientific findings, controversy may arise in the United States, since the discoveries are based on the principles of natural evolution. Indeed, some of those at the meeting warned that creationists may try to use the textbook revisions to advance their cause.

Deep Green was funded by the US National Science Foundation, the Department of Energy and the Department of Agriculture. The findings are available on: http://ucjeps.berkeley.edu/bryolab/gree nplantpage.html. Congress reports are available at:www.ibc99.org. RexDalton

\section{'Strengthened' Icelandic bioethics committee comes under fire}

[MUNICH] The government of Iceland has been accused of contravening an international convention by setting up a national bioethics committee whose members are selected exclusively by government departments.

The health minister announced last week that the new committee will immediately replace Iceland's existing seven-member bioethics committee. The latter was set up in 1997 , and its members were selected by the ministry from nominations put forward by the academic and medical communities.

Members of the new five-member committee will be selected without external nominations. Its main duties will be to approve research protocols involving patients - in particular, patient data held in a planned national health database which will be run by a private company - and to give general advice to politicians on the ethical aspects of medical treatments.

Officials defend the new arrangement for selecting committee members by saying that the new members would be free to speak their minds. But critics say it could mean that only individuals who support official policies are appointed.
Pétur Hauksson, vice-president of Mannvernd, the Association of Icelanders for Ethics in Medicine and Science, argues that the move contravenes the 1964 Helsinki agreement on Medical Research on Humans, which states that all research ethics committees should be independent of the researchers, those who initiate or finance the research and the relevant authorities. In this case, the government is the relevant authority because it is in charge of licensing out the database.

Hauksson is particularly concerned that a committee chosen by government officials "may not be able to give truly objective views and opinions on new government plans to further regulate health-sector databases and biobanks, and to revise personal privacy laws".

He also claims that the change was prompted by the government's desire to remove from the committee critics of the private company deCODE Genetics. The company is expected to be granted an exclusive 12-year licence by the government to create and market a national database combining genetic, health-care and genealogical information about Iceland's small population (see Nature 396,$395 ; 1998$ ).

Ingibjörg Pálmadóttir, Iceland's Minister of Health, and Sigurdur Gudmundsson, the director-general of public health, reject such criticisms. Pálmadóttir says the judgement of the bioethics committee will not be biased just because its members are selected by the government, and that the new regulations will strengthen the committee's power.

Vilhjálmur Arnason, director of the University of Iceland's Institute of Ethics, said on public radio last weekend that the change in selection procedures would not strengthen the committee, but would "strengthen the control of the government over the committee". He claimed that it was "almost too obvious" that the grounds for the change were the protection of the financial interests in the database project.

But Bogi Andersen, an Icelandic molecular geneticist working at the University of California, San Diego, and a vociferous critic of deCODE's plans for running the national database, says that parts of the new regulations are very positive, such as the likelihood that the bioethics commission would include a lay representative.

Alison Abbott 